\title{
Double balloon enteroscopy improves ERCP success in patients with modified small bowel anatomy
}

\author{
Goktug Sirin, (1) Sadettin Hulagu \\ Department of Gastroenterology, Kocaeli University Faculty of Medicine, Kocaeli, Turkey
}

\begin{abstract}
OBJECTIVE: The aim of this study was to evaluate the effect of double-balloon enteroscopy (DBE) on the success of endoscopic retrograde cholangiopancreatography (ERCP) procedures in patients with surgically modified gastrointestinal (GI) tract anatomy.

METHODS: The medical records of patients who underwent ERCP in the Gastroenterology Department of Kocaeli University School of Medicine hospital between December 2008 and September 2014 were examined. From the patient group that was scheduled to undergo DBE-ERCP, the details of cases in which ERCP via standard duodenoscope or DBE-ERCP was performed during the same session because standard ERCP failed were included. Procedure parameters, outcomes, and complications related to the procedure in both groups were analyzed. Patients who underwent the DBE-ERCP procedure directly, those who underwent push enteroscopy, or gastroscopy to evaluate the GI tract anatomy before the day of ERCP, and who underwent DBE-ERCP on a day other than the initial ERCP session were excluded. Afferent loop intubation, access to the major papilla, selective cannulation, therapeutic success rates, and the effect of DBE on overall procedure success were evaluated.

RESULTS: Fifty-one patients with a history of BII gastrojejunostomy and 11 patients with hepaticojejunostomy (with or without Roux-en-Y) were included in the study. In all patients, the ERCP procedure was initiated with a standard duodenoscope. If intubation of the afferent loop was unsuccessful in reaching the major papilla or enterobiliary anastomosis, DBE was used. In $30(48.4 \%)$ of the 62 patients whose GI tract was anatomically altered, the duodenoscope was successfully advanced to the ampulla and 27 (43.5\%) were cannulated successfully. Thirty-one patients underwent DBE-ERCP. DBE reached the ampulla or enterobiliary anastomosis in 30 patients $(96.8 \%)$ and selective choledocus cannulation was achieved in all patients but $3(90 \%)$, including 1 patient with a hepaticojejunostomy. The overall ERCP success rate increased from $43.5 \%(27 / 62)$ to 87.1\% (54/62). Two perforations (1 during standard duodenoscopy and 1 with DBE-ERCP) were observed.
\end{abstract}

CONCLUSION: The overall success rate of ERCP increased with use of the DBE technique in patients with small bowel anatomic variations that were the result of previous surgery.

Keywords: Billroth II gastric resection; double-balloon enteroscopy; endoscopic retrograde cholangiopancreatography; hepaticojejunostomy; Roux-en-Y reconstruction.

Cite this article as: Sirin G, Hulagu S. Double balloon enteroscopy improves ERCP success in patients with modified small bowel anatomy. North Clin Istanb 2020;7(2):131-139.

E ndoscopic retrograde cholangiopancreatography (ERCP) is a very useful procedure in the management of hepatobiliary system and pancreatic diseases. Although ERCP has been performed successfully in $85 \%$ to $95 \%$ of patients with normal small bowel anatomy [1], the success is lower in patients who have undergone a Billroth II (BII) gastrojejunostomy, and particularly in patients with a Roux-en-Y (R-en-Y) reconstruction with a long afferent limb (62-92\%) [2-4]. Implementation of this kind of reconstruction is common after ortho-

Received: December 11, 2019 Accepted: January 21, 2020 Online: February 10, 2020

Correspondence: Dr. Goktug SIRIN. Kocaeli Universitesi Tip Fakultesi, Gastroenteroloji Anabilim Dali, 41380 Kocaeli, Turkey.

Tel: +90 2623037575 e-mail: gsirin@live.com

(c) Copyright 2020 by Istanbul Provincial Directorate of Health - Available online at www.northclinist.com 
topic liver transplantation (OLT) or biliary diversion procedures; the endoscope is advanced to the site of the jejunojejunostomy and then an additional 40 to $80 \mathrm{~cm}$ to the Roux limb $[5,6]$. In R-en-Y cases, therapeutic choices for management of pancreaticobiliary diseases are percutaneous transhepatic cholangiography (PTC), ERCP, or surgery.

Double-balloon endoscopy (DBE) is a very useful endoscopic technique developed by Yamamoto et al. [7] in 2001 that allows for complete visualization and therapeutic interventions in the entire small intestine $[8,9]$. The impact of DBE in the management of hepatobiliary problems in patients with a history of hepatobiliary or pancreatic surgery has been described previously [4, 5, 10-12]. If PTC or re-surgery is not a valid option when the standard ERCP method has been unsuccessful, DBE can be a life-saving treatment alternative for these patients [13].

This is a description of clinical results of the use of DBE to perform ERCP (DBE-ERCP), including therapeutic actions to increase total ERCP success in patients with small bowel anatomy modified by surgery.

\section{MATERIALS AND METHODS}

The current study is a retrospective evaluation of prospectively entered data from a patient database of a single university center. The records of patients who had an anatomically altered gastrointestinal (GI) tract with or without a R-en-Y reconstruction who underwent ERCP between December 2008 and September 2014 were evaluated. Patient data were extracted from the registry system, where all information and follow-up results related to the ERCP procedure are prospectively entered and evaluated. Among the patients who had been scheduled to undergo DBE-ERCP, patients who underwent ERCP with a standard duodenoscope, and those who underwent DBE-ERCP during the same session because standard ERCP failed were enrolled in this study. Patients who underwent a DBE-ERCP procedure directly, those who underwent push enteroscopy or gastroscopy to evaluate the GI tract anatomy before the day of the ERCP procedure, and those who underwent DBEERCP on a day other than the initial ERCP session were excluded. No distinction was made between patients referred from other centers for a differential diagnosis and patients who initially presented at our clinics. The demographic characteristics of the patients, results of the radiological and biochemical evaluations performed prior to the procedure, procedure findings, data related to each procedure, histopathological diagnosis, clinical findings, and results were analyzed. Details of the afferent loop entrance, access to the ampulla, selective cannulation of the choledocus, therapeutic success rates, and the effect of DBE on overall procedure success were evaluated.

The DBE-ERCP technique and its risks were explained to all of the patients, and informed consent was obtained for endoscopic treatment. Approval for the study was received from the local ethics committee of Kocaeli University (KU/GOKAEK: 2019/326).

\section{Statistical Analysis}

All of the statistical analyses were performed using IBM SPSS Statistics for Windows, Version 20.0 (IBM Corp., Armonk, NY, USA). Descriptive statistics were reported as mean $\pm \mathrm{SD}$ values. Categorical variables were summarized as counts (percentages). Fisher's exact test was used to compare proportions between 2 samples. The statistical analyses were carried out with a $5 \%$ level of significance and a 2 -sided $\mathrm{p}$ value $<0.05$ was considered statistically significant.

\section{DBE-ERCP}

The ERCP procedure was initiated in all cases with a side-viewing (standard) duodenoscope. If it was not possible to perform an afferent loop entrance or reach the ampulla through biliary-pancreatic enteroanastomoses using the standard duodenoscope, ERCP with DBE was attempted before referring the patient for PTC or re-operation.

All of the DBE-ERCP procedures were performed under propofol sedation applied by an anesthesiology team, and 1 experienced endoscopist using a 200-cm therapeutic DBE system with a $2.8-\mathrm{mm}$ accessory channel (EN-450 T5; Fujifilm Corp., Tokyo, Japan). The push-and-pull technique was used, starting in the left lateral position and thereafter changing to the prone position, as described by Yamamoto and other authors [3, $7,8]$, under fluoroscopic guidance. An overtube and/or enteroscopy balloon was often used to keep the scope stabilized during the DBE-ERCP procedure.

\section{ERCP Procedures}

Long accessories for use with the long DBE system remain very limited in Turkey. Biliary cannulation of the hepatobiliary system was achieved with a Glo-Tip ERCP 
TABLE 1. Success and failure rate of ERCP using conventional side-viewing duodenoscope and DBE in different subgroups of our study population of patients with a planned DBE-ERCP procedure

\begin{tabular}{lccc} 
Nature of surgery $(\mathrm{n})$ & $\begin{array}{c}\text { Standard duodenoscope } \\
\text { success R/C/T (n) }\end{array}$ & $\begin{array}{c}\text { DBE-ERCP success } \\
\text { R/C/T (n) }\end{array}$ & $\begin{array}{c}\text { Success/Total } \\
(\mathrm{n})\end{array}$ \\
\hline Billroth II only (31) & $30 * * / 27 / 27$ & $*$ & $27 * * / 31$ \\
Billroth II+long afferenf limb (8) & $0 /-/-$ & $8 / 8 / 8$ & $8 / 8$ \\
Billroth II+acute angle of anastomosis of the afferent limb (6) & $0 /-/-$ & $6 / 6 / 6$ & $6 / 6$ \\
Billroth II+R-en-Y (6) & $0 /-/-$ & $6 / 4 / 4$ & $4 / 6$ \\
Hepatico-jejunostomy+R-en-Y (11) & $0 /-/-$ & $10 * * / 9 / 9$ & $9 * * / 11$ \\
Success/total (n) & $27 / 62(43.5 \%)$ & $27 / 31$ & $54 / 62(87.1 \%)$ \\
\hline
\end{tabular}

DBE: Double-balloon endoscopy; ERCP: Endoscopic retrograde cholangiopancreatography; *: Not attempted; **: Perforation; n: Patient number; R: Reaching to target point; C: Cannulation of hepatobiliary system or choledocus; R-en-Y: Roux-en-Y; T: Therapeutic intervention.

catheter (320-cm; Cook Medical Inc., Bloomington, IN, USA) and an Access 21 guidewire (650-cm; Cook Medical Inc., Bloomington, IN, USA). Contrast medium was administered for a cholangiogram and diagnostic analysis was performed. Papillary balloon dilation or initial bougienage of a stenotic ostium of the hepaticojejunostomy was performed using a controlled radial expansion (CRE) balloon dilatation catheter $(8-10 \mathrm{~mm}, \mathrm{CRE}$ PRO wireguided balloon dilatation catheter; Boston Scientific Corp., Marlborough, MA, USA), if necessary.

When a sphincterotomy (ES) was required, a 0.021-, 0.025 -, or 0.035 -in guidewire was advanced to the bile duct, and then ES was performed using an appropriate sphincterotome advanced over the guidewire. A papillotome (260 cm, CAN1-B3-18-260-35; Medwork Gmbh, Höchstadt/Aisch, Germany) was used with a with 0.021-in guidewire, the FTE-Papillotome (250 cm, F3QTEW1830250S (Fujifilm Corp., Tokyo, Japan) was used with a 0.025 -in guidewire, and the F3YTEW2230250-FR7-5-S or F3YBEW2225250FR7-5-15-S (250 cm; Fujifilm Corp., Tokyo, Japan) was used with a 0.035-in guidewire.

Biliary stones were extracted with a long biliary stone balloon (ESCORT II, $320 \mathrm{~cm}$; Cook Medical Inc., Bloomington, IN, USA).

When cannulation failed, the classic method was exchanged for the PTC-rendezvous technique, followed by trans-ampullary access as a rescue effort in another session. After percutaneous puncture inside the intrahepatic bile system, a 5-F sheath was entered via the guidewire in the bile duct and a 0.035-in guidewire was then moved through the ampulla. A therapeutic DBE was inserted up to the ampulla to carry out DBE-
ERCP. A 7-F nasobiliary catheter was placed in the bile duct for at least 24 hours to prevent bile leakage when this technique was used.

Antibiotics were not routinely administered before the procedure. Complications were defined according to the criteria reported by Cotton et al. [14].

\section{RESULTS}

\section{Patients}

Fifty-one patients with a BII gastrojejunostomy and 11 patients with a hepaticojejunostomy (with or without R-en-Y) were included in the study. ERCP was initiated using a standard duodenoscope in all cases. When entrance to the afferent loop was unsuccessful, and reaching the ampulla or enterobiliary anastomosis failed, DBE was applied. Among the 62 patients ( 41 male, 21 female; mean age: $61 \pm 12$ years; range: $31-78$ years) with an altered GI tract, the standard duodenoscope was successfully run out to the ampulla in 30 patients (48.4\%) with incomplete gastrectomy (BII, but no R-en-Y) and cannulation was performed without difficulty in 27 patients (43.5\%) (Table 1). The ampullary or anastomotic orifice was covered by a tumor in 2 patients. Selective biliary cannulation failed in these 2 patients $(3.2 \%)$ and they were successfully treated with PTC and drainage. Afferent loop perforation was encountered in 1 patient and recognized during the procedure. The final patient was treated with the PTC-rendezvous method followed by trans-ampullary access.

ERCP using a standard duodenoscope was unsuccessful in 31 patients $(50 \%)$ : failed afferent loop entrance in $6(9.7 \%)$, unsuccessful effort to reach the ampulla be- 
TABLE 2. DBE-ERCP characteristics in patients have anatomically altered GI tract with or without Roux-en-Y

\begin{tabular}{|c|c|c|c|}
\hline Anatomy $(n)$ & Indications & $\begin{array}{l}\text { Therapeutic } \\
\text { interventions }\end{array}$ & $\begin{array}{l}\text { ERCP success } \\
\quad(\text { Yes/No) }\end{array}$ \\
\hline $\begin{array}{l}\text { Hepaticojejunostomy R-en-Y for laparoscopic } \\
\text { cholecystectomy injury (6) }\end{array}$ & $\begin{array}{l}\text { Abdominal pain, fever, } \\
\text { elevated LFT, BS (3)/S (3) }\end{array}$ & $\begin{array}{l}\text { PAL, EBS-B (2), } \\
\text { dilation of stenosis (3) }\end{array}$ & $Y(5) / N(1)$ \\
\hline OLT, R-en-Y (2) & $\begin{array}{l}\text { Abdominal pain, } \\
\text { elevated LFT, BS (2) }\end{array}$ & $\begin{array}{l}\text { PAL, dilation of stenosis (1) } \\
\text { and EBS-B (2) }\end{array}$ & $Y(2)$ \\
\hline $\begin{array}{l}\text { Whipple, R-en-Y for chronic } \\
\text { pancreatitis (1) }\end{array}$ & Jaundice, abdominal pain, BS & $\begin{array}{l}\text { PAL, dilation of stenosis (1) } \\
\text { and EBS-B }\end{array}$ & Y \\
\hline $\begin{array}{l}\text { Whipple, R-en-Y for } \\
\text { pancreatic carcinoma (2) }\end{array}$ & $\begin{array}{c}\text { Cholestasis (1), } \\
\text { painless jaundice (1) }\end{array}$ & $\begin{array}{l}\text { EBS-B (1) and } \\
\text { dilation of stenosis (1) }\end{array}$ & $\begin{array}{c}Y(1) / \\
\text { perforation (1) }\end{array}$ \\
\hline $\begin{array}{l}\text { Billroth II for gastric ulcer (6) } \\
\text { with R-en-Y }\end{array}$ & $\begin{array}{l}\text { Jaundice, abdominal pain, } \\
\text { elevated LFT, BS (3)/ } \\
\text { painless jaundice PHT (3) }\end{array}$ & $\begin{array}{l}\text { LAL, sphincterotomy } \\
\text { and EBS-B (3), } \\
\text { and biliary stenting (3) }\end{array}$ & $Y(4) / N(2)$ \\
\hline Billroth II for gastric perforation (8) & $\begin{array}{l}\text { Painless jaundice (2), biliary duct } \\
\text { dilatation (3), C (3) }\end{array}$ & $\begin{array}{l}\text { LAL, sphincterotomy (3), } \\
\text { and biliary stenting (5) }\end{array}$ & $Y(8)$ \\
\hline Billroth II for gastric outlet obstruction ety? (6) & Chronic abdominal pain, BS (6) & Sphincterotomy (3) and EBS-B (5) & $Y(6)$ \\
\hline
\end{tabular}

DBE: Double-balloon endoscopy; ERCP: Endoscopic retrograde cholangiopancreatography; GI: Gastrointestinal; LFT: Liver function test; BS: Biliary stone; S: Stenosis PAL: Proximal afferent limb; EBS-B: Extraction of biliary stone by balloon; OLT: Orthotopic liver transplantation; LAL: Long afferent limb; PHT: Pancreatic head tumor; R-en-Y: Roux-en-Y; C: Cholangiocarcinoma.

cause of a long afferent loop in 8 (12.9\%), and failure to reach the pancreatobiliary anastomosis in 17 (27.4\%) who had a R-en-Y reconstruction (Table 1).

\section{Previous types of abdominal surgery}

In total, 17 (27.4\%) patients had undergone a previous R-en-Y reconstruction. Among the post-surgical patients who had a duodenoscope fail to access the ampulla or anastomotic orifice, 11 patients $(35.5 \%)$ had a hepaticojejunostomy, while 20 patients $(64.5 \%)$ had a normal papilla. The location of a pancreaticojejunostomy was not specifically sought. Anatomical features of the patients and DBE-ERCP indications are summarized in Table 2.

\section{Attainment of ampulla and anastomotic}

\section{orifice with DBE}

In all, a median of 5 (range: 3-10) DBE cycles were necessary to reach the ampulla or anastomotic orifice with DBE; the procedure was successful in 30 of 31 patients $(96.8 \%)$.

The average total operation time in the initial session was 92 minutes (range: 41-122 minutes), while the average time necessary to reach the ampulla or orifice was 41.7 minutes (range: $12-73$ minutes). Fluoroscopic images of patients with BII taken during ERCP using a

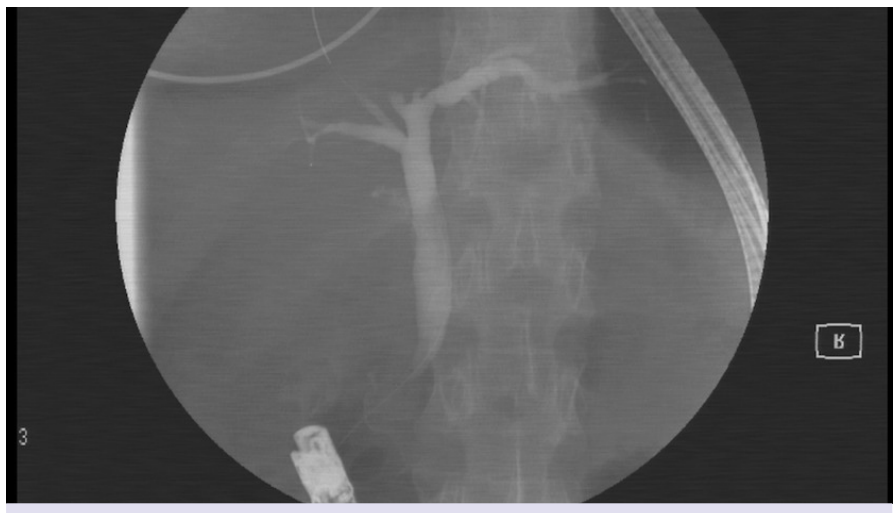

FIGURE 1. Normal cholangiogram image in a patient with billroth II gastric resection (using standard side-view duodenoscope).

standard duodenoscope are presented in Figures 1 and 2. Fluoroscopic images and endoscopic views of DBEERCP procedures are presented in Figures 3 and 4 and Figures 5 and 6, respectively.

Failure of DBE to access the ampulla or hepaticojejunostomy

In 1 patient (3.2\%), despite DBE-ERCP, access to the biliary canalicular system could not be obtained due to a 


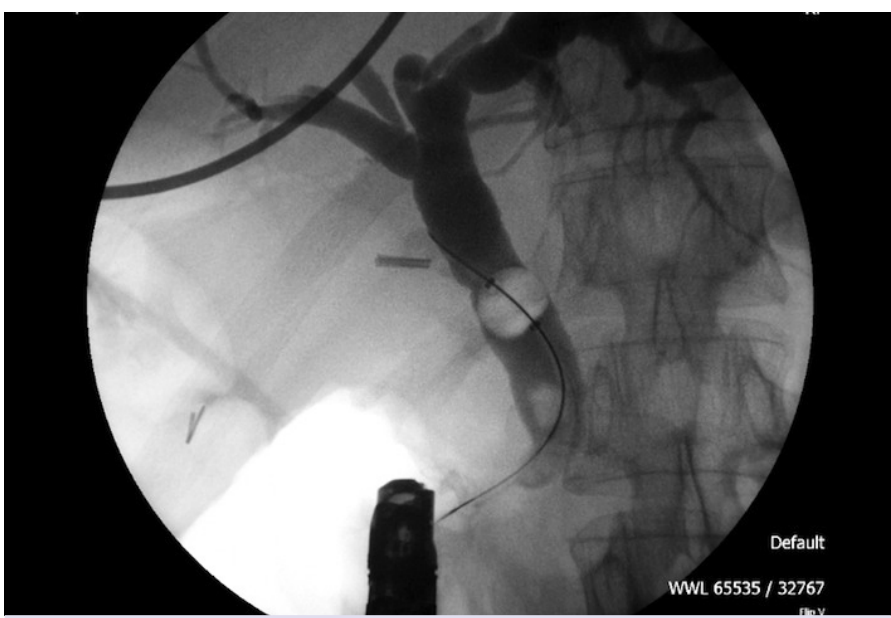

FIGURE 2. Biliary stone on cholangiogram in a patient with billroth II gastric resection and stone balloon application (using standard side-view duodenoscope).

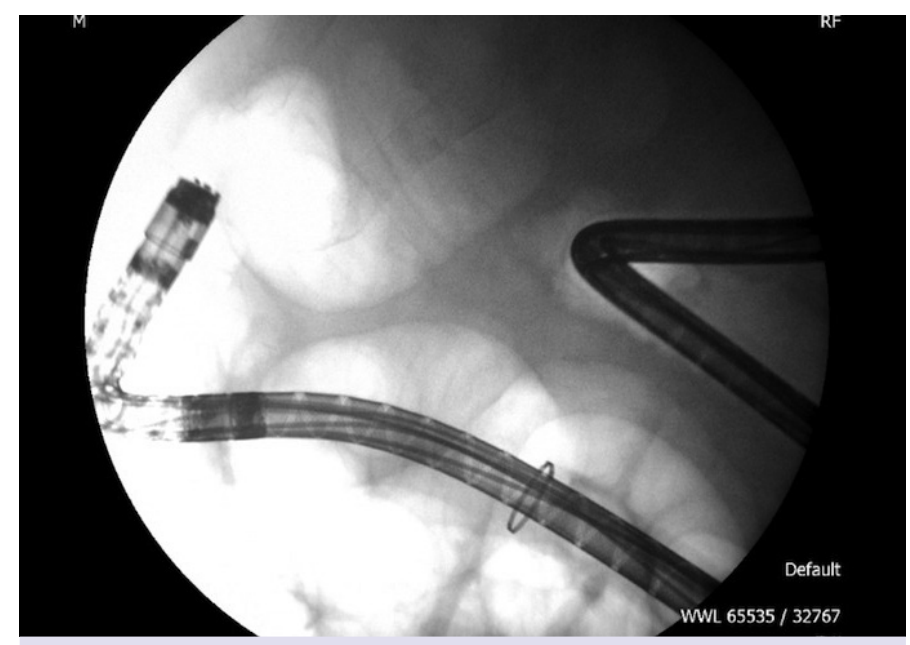

FIGURE 3. During DBE-ERCP procedure, DBE is advanced in the surgically modified small intestine (fluoroscopic view).

DBE: Double balloon enteroscopy; ERCP: Endoscopic retrograde cholangiopancreatography; DBE-ERCP: ERCP with DBE.

perforation that developed during the DBE-ERCP procedure. This patient was referred to surgery and subsequently recovered uneventfully.

\section{Interventions}

The DBE reached the ampulla in 30 patients (96.8\%) and cannulation of the common bile duct was successful in all but $3(87.1 \%)$. The ampullary orifice was covered with a tumor in 1 patient. When selective biliary cannulation failed in this patient $(3.2 \%)$, PTC and drainage proved successful. Afferent loop perforation was encountered in 1 patient, which was recognized during the procedure.

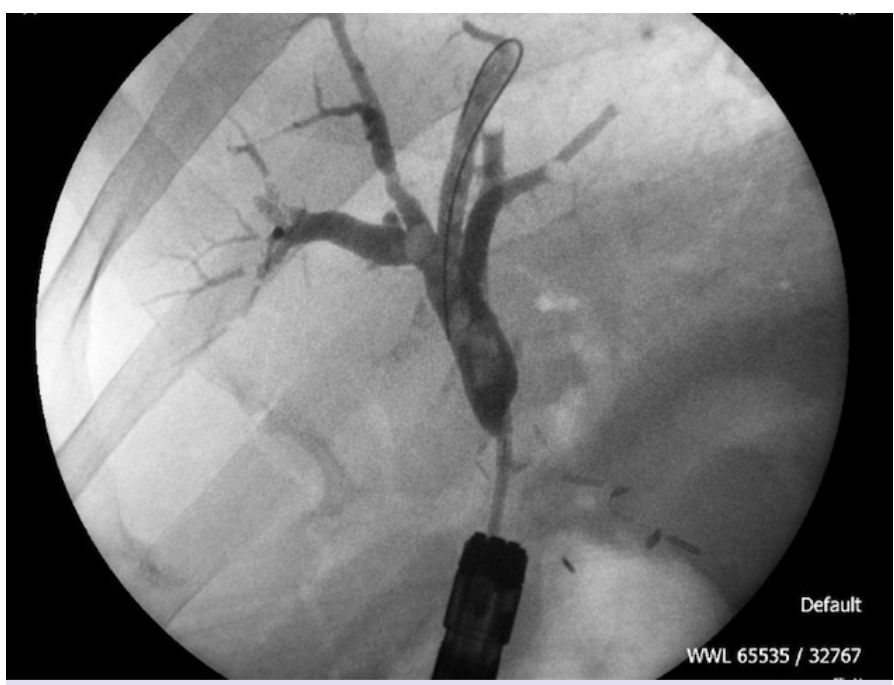

FIGURE 4. Cholangiography image in a patient with Hepaticojejunostomy who underwent liver resection for cholangiocarcinoma (procedure was performed with DBE, using accessories longer than standard ones).

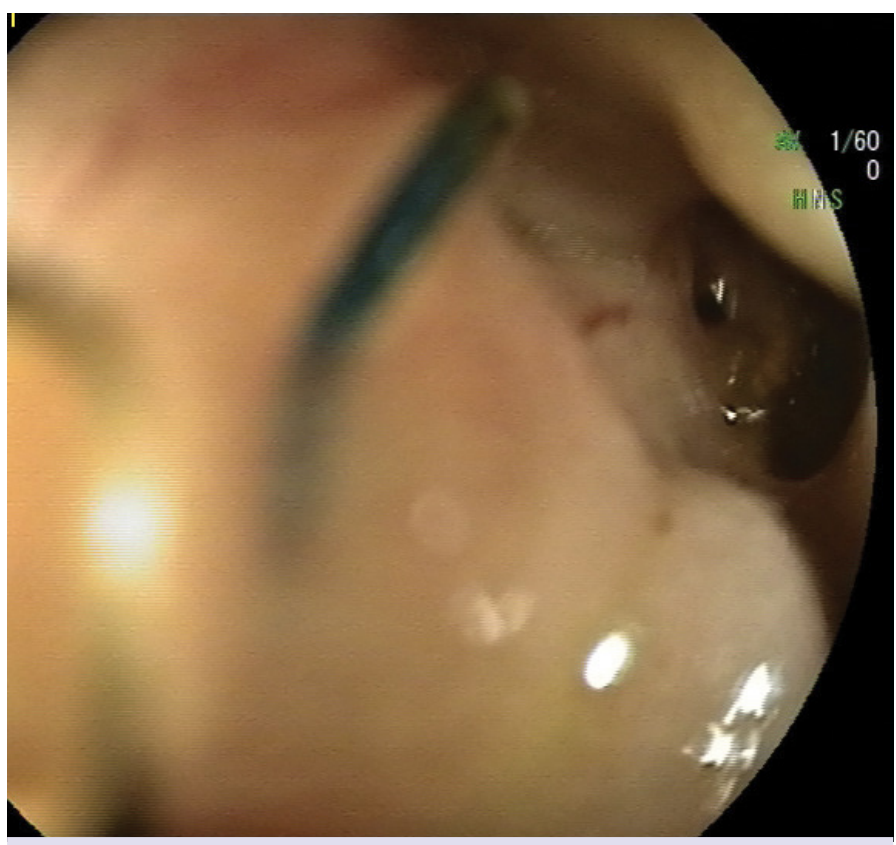

FIGURE 5. Endoscopic view of narrowed hepaticojejunostomy anastomosis opening (image was taken with DBE).

Two patients were treated with the PTC-rendezvous method, followed by trans-ampullary access.

In all, 35 DBE-ERCP procedures were performed in 27 patients who could not be completely investigated using the standard ERCP. Endoscopic treatment was successful in all 27 patients (100\%). The therapeutic interventions applied are shown in Table 2. 


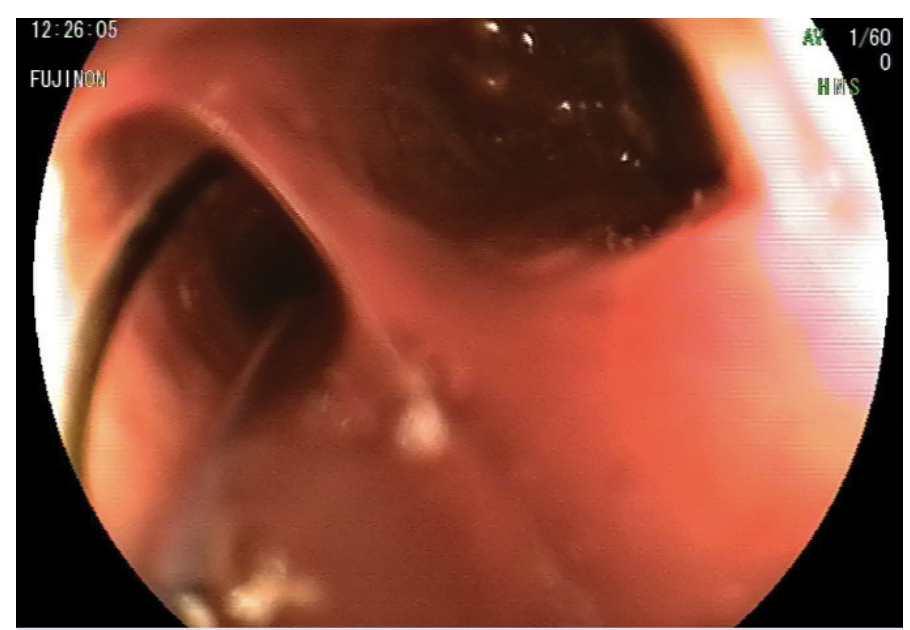

FIGURE 6. Enlargement in Hepaticojejunostomy anastomosis stricture after balloon dilatation (endoscopic view) (procedure was performed with DBE).

\section{Complications}

A patient who had a Whipple with R-en-Y for pancreatic carcinoma underwent surgery because of a small bowel perforation that occurred during DBE-ERCP. Retroperitoneal abscess developed in 1 patient who underwent a sphincterotomy and stone extraction using a balloon. He was discharged after 3 weeks of hospitalization without permanent sequelae, thanks to abscess drainage performed by the interventional radiology department along with antibiotic treatment.

No instances of cholangitis, clinically significant postERCP pancreatitis, or bleeding were observed in the DBE-ERCP patient group.

There were no serious complications or sequelae detected in the remaining patients. There was no patient death observed related to DBE-ERCP.

The overall success rate of standard ERCP increased with DBE-ERCP from $43.5 \%(27 / 62)$ to $87.1 \%$ $(54 / 62)$ in patients who had a history of small bowel surgery (BII alone, BII or hepaticojejunostomy plus Ren-Y) (Table 2). This increase was statistically significant $(\mathrm{p}<0.001)$.

\section{DISCUSSION}

ERCP is more difficult in patients with an anatomically altered GI tract. The challenges related to endoscopically reaching the hepatobiliary and pancreatic canalicular system in these patients have been described elsewhere $[3,6,10]$.
The success of ERCP using a duodenoscope in patients with previous GI tract surgery is very variable (BII, R-en-Y restoration, pancreaticojejunostomy, up to $92 \%$, $33 \%, 8 \%$, respectively) and high complication rates have been reported $[15,16]$. It is often unfeasible to perform ERCP in patients with a very long Roux limb due to surgery using a normal duodenoscope, especially if accompanying adhesions exist.

In the present study, the standard duodenoscope reached the papilla in 30 patients $(49.2 \%$ ) with BII (without R-en-Y) and therapeutic ERCP was successful in 27 (90\%) patients. Two cases $(6.4 \%)$ of failed retrograde biliary drainage were treated successfully with PTC. One patient was treated with the PTC-rendezvous method followed by the transampullary technique as a rescue approach in another session.

While previously published data indicated a cannulation success of a naive ampulla in $\mathrm{R}$-en-Y reconstruction of $57 \%$ [17, 18], Wright et al. [19] reported that they were able to perform therapeutic ERCP procedures in all cases without any problems if the ampulla was successfully reached with the standard duodenoscope (67\%).

In our study, among all patients who had a failed initial access to the papilla or orifice (50\%; afferent loop entrance, attaining the ampulla or pancreatobiliary anastomosis: $9.7 \%, 12.9 \%, 27.4 \%$, respectively) with the duodenoscope, a DBE-ERCP was used to advance toward to the ampulla in 30 patients $(96.7 \%)$ and therapeutic DBE-ERCP possible in $27(87.1 \%)$ patients. The rate of cannulation of the choledocus to the papilla or ostium was high in DBE patients.

DBE is a labor-intense and time-consuming procedure. However, as demonstrated in present study, this technique can be used in patients who have an altered small bowel. When DBE is used correctly, most of the time, the anastomotic orifice or ampulla could be accessed and detected visually. Our results are consistent with other published data regarding DBE in the literature $[3,15-16,20]$.

Aabakken et al. [3] noted a mean time to arrive at the last point of the Roux limb of 40 minutes (range: 5-120 minutes). These results were similar to our finding of a mean of 41.7 minutes (range: $12-73$ minutes). In our patients for whom therapeutic actions were applied, DBE-ERCP was successful in $87.1 \%(27 / 27)$ of cases.

ERCP for patients who have a GI tract with reorganized anatomy as a result of $\mathrm{R}-\mathrm{en}-\mathrm{Y}$ is associated with a high incidence of several complications, such as perfo- 
ration, or technical difficulties. The total complication, perforation, and mortality ratios have been reported as $8 \%$ to $13 \%, 0.65 \%$ to $11 \%$, and $1 \%$, respectively $[2,21]$. Most of these complications occurred in patients who had previously undergone BII gastrojejunostomy when performing ERCP using a standard duodenoscope due to an angled afferent loop and over-pushing of the scope. With DBE, compression on the small intestine wall and the sharp angulation of the anastomosis can be avoided and the enteroscope can be advanced more deeply, resulting in fewer complications than with the standard ERCP technique.

In a comparative study published by Kim et al. [22], the authors showed that use of a standard duodenoscope led to markedly more bowel perforations in patients with BII compared with a forward-viewing endoscope. We preferred to use a standard side-viewing scope first, which allowed the operators to view the ampulla by staying in front of it and use the accessories much more easily throughout the procedure. In our series, small bowel perforation occurred in 1 patient with a Whipple+ R-en-Y during DBE-ERCP and in another patient with choledocholithiasis during standard ERCP. These patients underwent surgery.

In case of failed ERCP in patients who have altered small bowel anatomy, a nonsurgical option is to perform PTC for biliary drainage in the period before DBE. PTC is a logical choice for patients who are not suitable for surgery, although there are some difficulties for patients who do not have a dilated intrahepatic biliary canal or those who have ascites. It is contraindicated in patients who have tense ascites or coagulation defects [23]. Furthermore, PTC is not a good option for patients who have disorders of the pancreas [11]. In these cases, DBE might be a unique management modality. The success rate in the literature varies between $64 \%$ and $100 \%$ for reaching the ampulla or the bilio-enteric anastomosis, which indicates that it can be used for diagnostic and therapeutic ERCP in this population [3, 24-27].

We know that PTC is associated with more morbidity and mortality compared with the routine endoscopic process [28-31]. The risk of complications during DBEERCP seems to be lower than that of PTC procedures, which is around 5\%, while therapeutic actions (balloon dilatation, biliary stent installation, or biliary stone therapy) have been performed successfully [30]. Thus, DBEERCP has an important capacity to manage benign or malign hepatobiliary and ampullary pathologies, even in patients who have history of small bowel surgery, and it can help to decrease the number of percutaneous procedures $[3,32,33]$. Our study confirmed that successful DBE-ERCP with a biliary drainage process led to a considerable decrease of cholestasis or cholangitis in 27 patients $(87.1 \%)$ and it was possible to avoid of PTC in these 27 patients.

It has been reported in the literature that at times, a naive ampulla or bilioenteric ostium may not be found even if the target point is reached with DBE $[26,27]$. We used a transparent cap in all procedures, which can aid in precise localization, and we did not have any case in which we could not find the ampulla or bilioenteric ostium.

In cases when the DBE-ERCP failed because the ampulla or ostium was covered by a tumor, this problem was managed by performing PTC followed by DBE-rendezvous procedure. After insertion of the percutaneous catheter inside the small bowel through the ampulla, this percutaneous cannula was successfully exchanged for an internal cannula entered via DBE in 2 patients.

A total of 17 patients who had a R-en-Y reconstruction underwent 20 ERCP sessions with DBE. A diagnosis and therapeutic interventions were successful in 15 of 17 cases (88.2\%) (1 perforation and 1 cannulation failure). Our findings show that successful cholangiography and management can be achieved by DBE-ERCP in these patients, which is consistent with the literature $[3,12,20,27]$.

From our point of view, cannulation and visualization of the biliary tree with DBE in patients with a hepaticojejunostomy can be performed more easily with a CRE balloon. This method is similar to the conventional papillotomy technique in patients with normal anatomy and seems to be less dangerous $[27,33]$. CRE balloons are marketed in different diameters and at the time of our study, 5 to $8-\mathrm{F}$ prostheses can be advanced throughout the $2.8-\mathrm{mm}$ diameter working channel of the therapeutic DBE.

In our study, the total success rate of duodenoscopic ERCP and DBE-ERCP in patients with an anatomically altered GI tract was $43.5 \%$ and $87.1 \%$, respectively. It is clear that the use of DBE-ERCP increases ERCP success.

Due to the increase in the number of patients undergoing biliary surgery and other measures for prolongation of life, DBE is increasingly used for ERCP. It is less invasive and safer than surgery or PTC, and it is largely effective in this group of patients $[34,35]$. Our study results showed that this method can be used successfully and safely for the diagnosis and treatment of hepatobiliary system pathologies despite complicated anatomy 
due to GI tract surgery. Moreover, these results also indicate that it is feasible to perform a rendezvous technique using DBE in patients with PTC, although in this study it was performed in just 2 patients.

The current version of DBE equipment has a new air pump system and 3.2-mm diameter working channel, which may be much more efficient in terms of easily performing ERCP procedure [36]. In addition, another new version that is smaller than the normal version and can be used with standard ERCP accessories is also available [37]. There is a need to evaluate these 2 new DBE systems in terms of the overall success rate and feasibility of the DBE-ERCP procedure. Our clinic is currently conducting such a study.

We believe that this paper is important because this is the one of very few series in Turkey that has investigated the impact of DBE-ERCP in patients who have an altered GI system. Nonetheless, our study has also some limitations. It was single-centered and was performed with relatively few patients, as in other studies of this subject. This may be problematic with respect to generalization of the study results. The retrospective nature creates a bias risk and raises the possibility of evaluation problems arising from the study design; however, we believe that evaluating data collected prospectively reduced this limitation. The current study was not designed to assess the effect of DBE-ERCP on the quality of life and the clinical status of patients during follow-up period. Given the lack of evaluation of long-term followup of the patients, it can be speculated that the definitive efficacy of therapeutic DBE-ERCP is unclear. Patients included in this analysis were a varied cohort of patients who had several forms of surgical operation. Therefore, there might be heterogeneity among patients in terms of procedural accomplishment ratios.

\section{Conclusion}

DBE-ERCP can be used in patients who have an anatomically altered GI tract (hepaticojejunostomy or BII gastrojejunostomy plus R-en-Y) after failure to enter the afferent loop or reach the ampulla or biliary-pancreatic enteroanastomosis using a standard duodenoscope. This technique is a useful, secure, and efficient procedure in patients with complicated anatomy secondary to previous surgery that permits diagnostic and therapeutic action. DBE-ERCP maximizes the total success ratio of ERCP in these patients, although complications can occur even in skilled and experienced hands.
Ethics Committee Approval: All procedures performed in studies involving human participants were in accordance with the ethical standards of the institutional and/or national research committee and with the 1964 Helsinki declaration and its later amendments or comparable ethical standards (KU/GOKAEK date: November 13, 2019, number: 2019/326).

Informed Consent: Informed consent was obtained from all individual participants included in the study.

Conflict of Interest: No conflict of interest was declared by the authors.

Financial Disclosure: The authors declared that this study has received no financial support.

Authorship Contributions: Concept - GS, SH; Design - GS, SH; Supervision - GS, SH; Materials - GS, SH; Data collection and/or processing - GS, SH; Analysis and/or interpretation - GS; Literature review - GS; Writing - GS; Critical review - GS, SH.

\section{REFERENCES}

1. Farrell RJ, Howell DA, Pleskow DK. New technology for endoscopic retrograde cholangiopancreatography: improving safety, success, and efficiency. Gastrointest Endosc Clin N Am 2003;13:539-59. [CrossRef]

2. Osnes M, Rosseland AR, Aabakken L. Endoscopic retrograde cholangiography and endoscopic papillotomy in patients with a previous Billroth-II resection. Gut 1986;27:1193-8. [CrossRef]

3. Aabakken L, Bretthauer M, Line PD. Double-balloon enteroscopy for endoscopic retrograde cholangiography in patients with a Roux-en-Y anastomosis. Endoscopy 2007;39:1068-71. [CrossRef]

4. Liu K, Joshi V, Saxena P, Kaffes AJ. Predictors of success for double balloon-assisted endoscopic retrograde cholangiopancreatography in patients with Roux-en-Y anastomosis. Dig Endosc 2017;29:190-7.

5. Verdonk RC, van den Berg AP, Slooff MJ, Porte RJ, Haagsma EB. Liver transplantation: an update. Neth J Med 2007;65:372-80.

6. Ciçek B, Parlak E, Dişibeyaz S, Koksal AS, Sahin B. Endoscopic retrograde cholangiopancreatography in patients with Billroth II gastroenterostomy. J Gastroenterol Hepatol 2007;22:1210-3. [CrossRef]

7. Yamamoto H, Sekine Y, Sato Y, Higashizawa T, Miyata T, Iino S, et al. Total enteroscopy with a nonsurgical steerable double-balloon method. Gastrointest Endosc 2001;53:216-20. [CrossRef]

8. Kita H, Yamamoto H. New indications of double balloon endoscopy. Gastrointest Endosc 2007;66:S57-9. [CrossRef]

9. Hulagu S, Sirin G. Double balloon endoscopy and its role in current gastroenterology practice. Turkiye Klinikleri J GastroenterohepatolSpecial Topics 2012;5:78-87.

10. Chu YC, Su SJ, Yang CC, Yeh YH, Chen CH, Yueh SK. ERCP plus papillotomy by use of double-balloon enteroscopy after Billroth II gastrectomy. Gastrointest Endosc 2007;66:1234-6. [CrossRef]

11. Chahal P, Baron TH, Topazian MD, Petersen BT, Levy MJ, Gostout CJ. Endoscopic retrograde cholangiopancreatography in post-Whipple patients. Endoscopy 2006;38:1241-5. [CrossRef]

12. Mönkemüller K, Fry LC, Bellutti M, Neumann H, Malfertheiner P. ERCP with the double balloon enteroscope in patients with Roux-en-Y anastomosis. Surg Endosc 2009;23:1961-7. [CrossRef]

13. Shao XD, Qi XS, Guo XZ. Endoscopic retrograde cholangiopancreatography with double balloon enteroscope in patients with altered gastrointestinal anatomy: A meta-analysis. Saudi J Gastroenterol 2017;23:150-60. 
14. Cotton PB, Lehman G, Vennes J, Geenen JE, Russell RC, Meyers WC, et al. Endoscopic sphincterotomy complications and their management: an attempt at consensus. Gastrointest Endosc 1991;37:383-93.

15. Faylona JM, Qadir A, Chan AC, Lau JY, Chung SC. Small-bowel perforations related to endoscopic retrograde cholangiopancreatography (ERCP) in patients with Billroth II gastrectomy. Endoscopy 1999;31:546-9. [CrossRef]

16. Haruta H, Yamamoto H, Mizuta K, Kita Y, Uno T, Egami S, et al. A case of successful enteroscopic balloon dilation for late anastomotic stricture of choledochojejunostomy after living donor liver transplantation. Liver Transpl 2005;11:1608-10. [CrossRef]

17. Hintze RE, Adler A, Veltzke W, Abou-Rebyeh H. Endoscopic access to the papilla of Vater for endoscopic retrograde cholangiopancreatography in patients with billroth II or Roux-en-Y gastrojejunostomy. Endoscopy 1997;29:69-73. [CrossRef]

18. Elton E, Hanson BL, Qaseem T, Howell DA. Diagnostic and therapeutic ERCP using an enteroscope and a pediatric colonoscope in longlimb surgical bypass patients. Gastrointest Endosc 1998;47:62-7.

19. Wright BE, Cass OW, Freeman ML. ERCP in patients with long-limb Roux-en-Y gastrojejunostomy and intact papilla. Gastrointest Endosc 2002;56:225-32. [CrossRef]

20. Pohl J, May A, Aschmoneit I, Ell C. Double-balloon endoscopy for retrograde cholangiography in patients with choledochojejunostomy and Roux-en-Y reconstruction. Z Gastroenterol 2009;47:215-9. [CrossRef]

21. Freeman ML. Complications of endoscopic biliary sphincterotomy: a review. Endoscopy 1997;29:288-97. [CrossRef]

22. Kim MH, Lee SK, Lee MH, Myung SJ, Yoo BM, Seo DW, et al. Endoscopic retrograde cholangiopancreatography and needle-knife sphincterotomy in patients with Billroth II gastrectomy: a comparative study of the forward-viewing endoscope and the side-viewing duodenoscope. Endoscopy 1997;29:82-5. [CrossRef]

23. Teplick SK, Flick P, Brandon JC. Transhepatic cholangiography in patients with suspected biliary disease and nondilated intrahepatic bile ducts. Gastrointest Radiol 1991;16:193-7. [CrossRef]

24. Spahn TW, Grosse-Thie W, Spies P, Mueller MK. Treatment of choledocholithiasis following Roux-en-Y hepaticojejunostomy using doubleballoon endoscopy. Digestion 2007;75:20-1. [CrossRef]

25. Maaser C, Lenze F, Bokemeyer M, Ullerich H, Domagk D, Bruewer M, et al. Double balloon enteroscopy: a useful tool for diagnostic and therapeutic procedures in the pancreaticobiliary system. Am J Gastroenterol 2008;103:894-900. [CrossRef]

26. Mönkemüller K, Bellutti M, Neumann H, Malfertheiner P. Therapeu- tic ERCP with the double-balloon enteroscope in patients with Rouxen-Y anastomosis. Gastrointest Endosc 2008;67:992-6. [CrossRef]

27. Parlak E, Ciçek B, Dişibeyaz S, Cengiz C, Yurdakul M, Akdoğan M, et al. Endoscopic retrograde cholangiography by double balloon enteroscopy in patients with Roux-en-Y hepaticojejunostomy. Surg Endosc 2010;24:466-70. [CrossRef]

28. Park JS, Kim MH, Lee SK, Seo DW, Lee SS, Han J, et al. Efficacy of endoscopic and percutaneous treatments for biliary complications after cadaveric and living donor liver transplantation. Gastrointest Endosc 2003;57:78-85. [CrossRef]

29. Schumacher B, Othman T, Jansen M, Preiss C, Neuhaus H. Long-term follow-up of percutaneous transhepatic therapy (PTT) in patients with definite benign anastomotic strictures after hepaticojejunostomy. Endoscopy 2001;33:409-15. [CrossRef]

30. Winick AB, Waybill PN, Venbrux AC. Complications of percutaneous transhepatic biliary interventions. Tech Vasc Interv Radiol 2001;4:200-6. [CrossRef]

31. Hamlin JA, Friedman M, Stein MG, Bray JF. Percutaneous biliary drainage: complications of 118 consecutive catheterizations. Radiology 1986;158:199-202. [CrossRef]

32. Ishii K, Itoi T, Tonozuka R, Itokawa F, Sofuni A, Tsuchiya $T$, et al. Balloon enteroscopy-assisted ERCP in patients with Roux-en-Y gastrectomy and intact papillae (with videos). Gastrointest Endosc 2016;83:377-86. [CrossRef]

33. Sato T, Kogure H, Nakai Y, Ishigaki K, Hakuta R, Saito K, et al. Double-balloon endoscopy-assisted treatment of hepaticojejunostomy anastomotic strictures and predictive factors for treatment success. Surg Endosc. 2019 Jun 19, Epub ahead of print, [doi: 10.1007/s00464-01906924-6]. [CrossRef]

34. Farrell J, Carr-Locke D, Garrido T, Ruymann F, Shields S, Saltzman J. Endoscopic retrograde cholangiopancreatography after pancreaticoduodenectomy for benign and malignant disease: indications and technical outcomes. Endoscopy 2006;38:1246-9. [CrossRef]

35. Lee A, Shah JN. Endoscopic approach to the bile duct in the patient with surgically altered anatomy. Gastrointest Endosc Clin N Am 2013;23:483-504. [CrossRef]

36. Moreels TG. Update in enteroscopy: New devices and new indications. Dig Endosc 2018;30:174-81. [CrossRef]

37. Cheung SW, Cheng KS, Yip WM, Li KK. Feasibility of short doubleballoon enteroscopy-assisted endoscopic retrograde cholangiopancreatography in patients with surgically altered gastrointestinal anatomy: experience in a regional centre. Hong Kong Med J 2017;23:648-50. 